\title{
The effect of consequent exposure of stress and dermal application of low doses of chlorpyrifos on the expression of glial fibrillary acidic protein in the hippocampus of adult mice
}

\author{
Kian Loong Lim ${ }^{1 \dagger}$, Annie Tay ${ }^{2 \dagger}$, Vishna Devi Nadarajah ${ }^{3 \dagger}$, Nilesh Kumar Mitra ${ }^{3 *}$
}

\begin{abstract}
Background: Chlorpyrifos (CPF), a commonly used pesticide worldwide, has been reported to produce neurobehavioural changes. Dermal exposure to CPF is common in industries and agriculture. This study estimates changes in glial fibrillary acidic protein (GFAP) expression in hippocampal regions and correlates with histomorphometry of neurons and serum cholinesterase levels following dermal exposure to low doses of CPF with or without swim stress.
\end{abstract}

Methods: Male albino mice were separated into control, stress control and four treatment groups $(n=6)$. CPF was applied dermally over the tails under occlusive bandage ( 6 hours/day) at doses of 1/10th (CPF 0.1 ) and 1/5th dermal LD $\mathrm{L}_{50}$ (CPF 0.2) for seven days. Consequent treatment of swim stress followed by CPF was also applied. Serum cholinesterase levels were estimated using spectroflurometric methods. Paraffin sections of the left hippocampal regions were stained with $0.2 \%$ thionin followed by the counting of neuronal density. Right hippocampal sections were treated with Dako Envision GFAP antibodies.

Results: CPF application in 1/10th $\mathrm{LD}_{50}$ did not produce significant changes in serum cholinesterase levels and neuronal density, but increased GFAP expression significantly ( $p<0.001$ ). Swim stress with CPF 0.1 group did not show increase in astrocytic density compared to CPF 0.1 alone but decreased neuronal density.

Conclusions: Findings suggest GFAP expression is upregulated with dermal exposure to low dose of CPF. Stress combined with sub-toxic dermal CPF exposure can produce neurotoxicity.

\section{Background}

Almost $85 \%$ of the 2.6 million metric tonnes of active components of pesticides manufactured every year is used in commercial farming [1]. Occupational pesticide poisoning is an important risk factor for farmers as they are constantly being exposed to pesticides. It has also been found that most occupational exposures are dermal [2]. CPF (O, O-diethyl O-3, 5, 6-trichloro-2-pyridyl phosphorothioate) is a broad spectrum organophosphate pesticide. It inhibits the enzyme cholinesterase by binding irreversibly to, and phosphorylating its active site.

\footnotetext{
* Correspondence: nileshkumar_mitra@imu.edu.my

† Contributed equally

${ }^{3}$ Human Biology Department, International Medical University, No.126, Jalan 19/155B, Bukit Jalil, 57000,Kuala Lumpur, Malaysia

Full list of author information is available at the end of the article
}

A report in 2001 by the United States Environmental Protection Agency on pesticide use approximates that 50 to $60 \%$ of the total $11-16$ million pounds of $\mathrm{CPF}$ used in the US was for agriculture [3].

In chronic low-level exposures of CPF, crop workers recorded a reduced performance in neurobehavioral tests [4]. Individuals with histories of exposure to low, sub-clinical levels of chlorpyrifos have also reported reduced levels of concentration, word finding and shortterm-memory impairment [5]. CPF has also been reported to produce neurobehavioral and morphological damages in the nervous systems of animals during embryonic life through to postnatal development [6,7]. Previous work by the authors has found that sub-toxic doses $(1 / 5$ th and $1 / 2 \mathrm{LD}_{50}$ ) of chlorpyrifos applied dermally for 3 weeks can 
produce significant hippocampal neuronal loss, and that stress can exacerbate this damage [8]. Even the inhibition of serum cholinesterase which was reduced by $76 \%$ with dermal application of CPF in the dose of $1 / 5$ th dermal $\mathrm{LD}_{50}$ for 21 days got exaggerated by addition of swim stress at $38^{\circ} \mathrm{C}$ by $19.7 \%$.

The biological efficacy of many toxicants can be exacerbated by exposure to heat stress [9]. Administration of pyridostigmine, a carbamate AChE inhibitor normally impermeable to the blood brain barrier (BBB), during the Persian Gulf War, resulted in an increase in the occurrences of reported CNS symptoms by more than threefold, indicating a possible link between stress and increased BBB permeability [10].

One of the proteins associated with neuronal damage is glial fibrillary acidic protein (GFAP). GFAP is a cytoplasmic intermediate filament protein found in astrocytes. They maintain the structural integrity of astrocytes, especially when these cells undergo hypertrophy and hyperplasia in response to a non-invasive CNS injury [11] whereby, expression of GFAP is upregulated [12]. A characteristic feature of gliosis, GFAP upregulation often occurs in response to injury in the brain [13]. Numerous neurological studies have associated CNS damage with increased GFAP expression [12,13]. It has also been suggested that GFAP is a sensitive and early biomarker of neurotoxicity, its up-regulation preceding anatomically perceptible damages in the brain [14-16]. Predominantly, only studies investigating developmental or in utero exposure to CPF have estimated GFAP expression $[17,18]$. The effect of dermal application of CPF on GFAP expression in the hippocampus has not been reported.

The aim of this study was to determine the expression of GFAP in the hippocampal region of adult mice following consequent exposure of repeated stress and dermal application of low dose chlorpyrifos for small duration (7 days), and to correlate the findings with changes in serum cholinesterase and neuronal density of Cornu Ammonis of hippocampus. The study aimed to look into the changes in the above parameters with reference to our previous findings [8] with dermal application of subtoxic doses of CPF with swim stress for a relatively prolonged period of 21 days.

\section{Methods}

Commercial preparations of CPF (O, O-diethyl O-3, 5, 6-trichloro-2-pyridyl phosphorothioate), Zespest, manufactured in Kuala Lumpur, Malaysia was used in this study. This preparation contained $38.7 \% \mathrm{~W} / \mathrm{W}$ CPF diluted in xylene. The mixture was further diluted in xylene to prepare doses of $1 / 10$ th $\mathrm{LD}_{50}(20.2 \mathrm{mg} / \mathrm{kg}$ body weight CPF in $1 \mathrm{~mL})$ and $1 / 5$ th $\mathrm{LD}_{50}(40.4 \mathrm{mg} / \mathrm{kg}$ body weight CPF in $1 \mathrm{~mL}$ ) CPF solution.
Male Swiss albino mice (species: ICR), 60 days old (30$32 \mathrm{~g}$ ) were used in this study. They were housed in plastic cages (six in a cage) and were exposed to natural, twelvehourly light and dark sequence. Lab chow (pellet feed) and water were given ad libitum. Animal experiments adhered to the principles stated in the guide-book of laboratory animal care and user committee of the International Medical University and in accordance with the declaration of Helsinki. The mice were divided into six groups $(n=6)$. Control group was applied with xylene, CPF0.1 group was applied with $1 / 10$ th $\mathrm{LD}_{50}$ of CPF and CPF0.2 group was applied with $1 / 5$ th $\mathrm{LD}_{50}$ of CPF. Swim stress at $38^{\circ} \mathrm{C}$ followed by application over the tails with xylene (Control s), 1/10th $\mathrm{LD}_{50}$ CPF (CPF $0.1 \mathrm{~s}$ ) and $1 / 5$ th $\mathrm{LD}_{50} \mathrm{CPF}$ (CPF $0.2 \mathrm{~s}$ ) was also done. All the 6 groups were used in the experiment which lasted 1 week only.

CPF solution was applied directly to the tail of the mice under occlusive bandage. Animals were exposed to CPF daily for 1 week. Absorptive surgical gauze soaked with either xylene (control) or $1 \mathrm{ml}$ of CPF solution (1/10th or $1 / 5$ th $\mathrm{LD}_{50}$ ) was wrapped around the tail. Aluminium foil was then wrapped over to prevent vaporisation of the CPF solution. The foil wrappings were left on the tail for 6 hours. After removal of the wrappings, traces of CPF solution were removed by dipping the tails of all mice in clean water.

A plastic container measuring $30 \mathrm{~cm} \times 30 \mathrm{~cm} \times 40 \mathrm{~cm}$ was filled with water to a depth of $30 \mathrm{~cm}$. The water was heated to a temperature of $38^{\circ} \mathrm{C}$. The animals were then placed in the water for a swim session lasting 6 minutes [19]. After the session of forced-swimming, the mice were dried and allowed to rest for approximately $15 \mathrm{~min}$ utes before the CPF solution was applied to their tails as previously described.

Body weight was measured at the beginning and end of both experimental periods. At the end of 7 days, the animals were anaesthetized with intraperitoneal administrations of pentobarbitone. Blood samples were collected for cholinesterase and corticosterone assay. Brain tissues were collected for histomorphometric studies and GFAP immunohistochemical staining.

\section{Serum cholinesterase assay}

The Amplex Red Acetylcholine/Acetylcholinesterase assay kit from Molecular probes Inc. USA (Invitrogen detection technologies, A12217) was used to estimate serum cholinesterase activity using a fluorescence microplate reader. A working solution of $400 \mu \mathrm{M}$ Amplex Red reagent containing $2 \mathrm{U} / \mathrm{mL}$ Horse Radish Peroxidase (HRP), $0.2 \mathrm{U} / \mathrm{mL}$ choline oxidase and $100 \mu \mathrm{M}$ Acetylcholine (ACh) was prepared from the stock solutions. The reaction began when $100 \mu \mathrm{L}$ of the working solution was added to each well containing the serum samples and controls diluted to 
$40 \times$. Serum samples and controls were tested in duplicates. Fluorescence emitted by the individual samples was measured in a microplate reader at an excitation of $560 \mathrm{~nm}$ and emission detection at $590 \mathrm{~nm}$. Background fluorescence was eliminated by subtracting values derived from the negative control. To obtain a standard curve, cholinesterase concentrations of the standards and their corresponding fluorescence readings were converted to $\log _{10}$ values before being plotted against each other. This was done to facilitate regression analysis of the data. Using the standard curve, serum concentrations of cholinesterase from the samples of different groups were then calculated.

\section{Serum corticosterone assay}

The corticosterone enzyme immunoassay (EIA) kit from Cayman Chemicals (No. 10005590) was used. This assay used a corticosterone tracer which was a corticosteronecholinesterase conjugate. The well-plates were coated with mouse monoclonal anti-rabbit IgG. Corticosterone in the serum sample and the corticosterone tracer provided in the kit compete for limited numbers of corticosteronespecific rabbit anti-serum binding sites. The plates were washed to remove the unbound reagents and then Ellman's reagent was employed to estimate cholinesterase. The colour produced by this enzymatic reaction measured in a fluorescence microplate reader at an absorbance of $405 \mathrm{~nm}$ was proportional to the amount of corticosteronetracer bound to the well. The amount of free corticosterone present in the well was inversely proportional to the amount of emission. The purification of serum samples was not employed as two dilutions, $20 \times$ and $40 \times$, showed good correlation in the amount of final corticosterone. The logit $\left(\mathrm{B} / \mathrm{B}_{0}\right)$ values were calculated by dividing absorbance values of every standard well (B) by the average value of maximum binding wells $\left(\mathrm{B}_{0}\right)$. To obtain standard curve, concentration standards were plotted against logit values. Logit of the data was then employed in Microsoft Excel to get the serum concentrations of corticosterone by substitution in the linear regression analysis.

\section{Histomorphometric studies and estimation of GFAP expression}

Perfusion of the brains was carried out using $10 \%$ formal saline. The area between the optic chiasma and infundibulum in which the hippocampus is located was further dissected followed by paraffin processing. Right sagittal half was used for GFAP immunohistochemical staining. Coronal serial sections from the left half of the hippocampal area, 8 micron thick, were stained with Nissl stain $\left(0.2 \%\right.$ thionin in acetate buffer). Every $10^{\text {th }}$ section in each animal was selected. Using Nikon's Brightfield Compound Microscope, YS100 (attached with Nikon camera), the slides were examined and photographed under $400 \times$ objective. For each slide, two random areas of CA1, one random area of CA2 and two random areas of CA3 were examined. Neuronal counts were then performed in the regions of the hippocampus as mentioned above within a measured square area of $160 \times 160 \mu \mathrm{m}$. Only neurons with a clearly defined border and visible single nucleus were counted. 10 random neuronal nuclear diameters were also taken for each region. The neuronal counts were then used to obtain the absolute density $(\mathrm{P})$, of neuronal nucleus per unit area of section using the Abercrombie formula: $\mathrm{P}=\mathrm{A}$. $\mathrm{M} / \mathrm{L}+\mathrm{M} ; \mathrm{M}=$ Section thickness in micron; $\mathrm{L}=$ Mean nuclear diameter of respective area; $\mathrm{A}=$ Neuronal count [20]. The neuronal density per unit area $\left(\mathrm{mm}^{2}\right)$ was then calculated.

Three stained slides containing hippocampal areas (every $27^{\text {th }}$ section) were chosen for each animal. DakoCytomation Envision+ system together with polyclonal rabbit Anti-glial Fibrillary Acid Protein (GFAP) antibody were used to estimate GFAP expression in the hippocampal sections. This antibody could be used to identify astrocytes by light microscopy. Following dewaxing by xylene, 4 micron thick sections were gradually rehydrated. Then washing was done by Tris-buffered saline with Tween (TBST). The peroxidise was blocked followed by application of antiGFAP antibody. The polymer was added to bind with the primary antibody which was followed by application of chromogen. Ultimately Haematoxylin counterstain was employed followed by dehydration, clearing and mounting. Using Nikon's Brightfield Compound Microscope, YS100 (attached with Nikon camera), the slides were viewed and photographed under $400 \times$ objective. For each slide, three random areas in the stratum moleculare-lacunosum and two random areas in stratum oriens of the hippocampus were examined. The areas of the captured images were constant. Astrocytic cell counts were then performed in the regions of the hippocampus as mentioned above within a measured square area of $200 \times 200 \mu \mathrm{m}$. Only cells with a clearly defined nuclear border and radiating processes containing GFAP staining were counted. The density of astrocytes per unit area $\left(\mathrm{mm}^{2}\right)$ was then calculated.

\section{Statistical analysis}

Mean serum cholinesterase levels of individual mouse under different groups were subjected to one way ANOVA statistical analysis using SPSS 11.5. Inter-group significance was tested by Post Hoc LSD test, provided ANOVA showed significant difference between the groups. The mean absolute counts $\left(\right.$ per $\mathrm{mm}^{2}$ ) of the neuronal count and astrocytes were subjected to One Way ANOVA statistical analysis to identify any statistically significant differences in the counts between the treatment groups. Post hoc Bonferroni was employed to determine the level of significance in inter-group difference. 


\section{Results}

\section{Changes in serum cholinesterase}

Cholinesterase activity was reduced by $30.5 \%$ with exposure to $\mathrm{CPF}$ in $1 / 10$ th dermal $\mathrm{LD}_{50}$ compared to the normal group. With dermal application of CPF in 1/5th $\mathrm{LD}_{50}$ for 7 days, a significant reduction $(\mathrm{p}<0.05$, One way ANOVA, post hoc LSD) by $80.25 \%$ in serum cholinesterase activity was observed (Figure 1). Thus a dosedependent depletion in the activity of serum cholinesterase was observed. Swim stress followed by dermal CPF application caused further depletion in cholinesterase activity by $19.3 \%$ (CPF $0.1 \mathrm{~s}$ ) and $0.4 \%$ (CPF $0.2 \mathrm{~s}$ ) respectively compared to CPF $0.1\left(1 / 10\right.$ th $\left.L_{50}\right)$ and CPF $0.2\left(1 / 5\right.$ th $\left.\mathrm{LD}_{50}\right)$ groups. However, both these changes observed in swim stress groups were not statistically significant. Application of swim stress for 7 days in control (s) group, increased serum cholinesterase activity by $25 \%$ compared to the control group. Both the groups with stress + application of CPF (CPF $0.1 \mathrm{~s}$ and CPF $0.2 \mathrm{~s}$ ) showed statistically significant reduction in cholinesterase activity $(\mathrm{p}<0.05$, One way ANOVA, post hoc LSD) compared to the control and swim stress only group (Control s).

\section{Changes in serum corticosterone}

Elevation of serum corticosterone levels confirmed that forced swim stress daily for six minutes was sufficient to induce stress in the experimental mice. While application of both doses of CPF failed to increase serum corticosterone, the groups with swim stress (control s, CPF $0.1 \mathrm{~s}$, CPF 0.2 s) showed higher corticosterone levels compared to the control group (Figure 2) by 30\%, 27.8\% and 43\% respectively. Mice group with only swim stress showed $30 \%$ increase in the serum corticosterone level compared to the control.

\section{Changes in histological and histomorphometric studies}

Upon qualitative observations of the hippocampal pyramidal neurons, the group receiving $1 / 10$ th $\mathrm{LD}_{50} \mathrm{CPF}$ for 1 week (CPF 0.1) showed only few pyknosed neurons. Quantitative study showed that the neuronal count reduced significantly $(\mathrm{p}<0.05)$ compared to the control group only in CA3 hippocampal region (Table 1). In contrast, when swim stress was applied prior to CPF exposure at the same dose (CPF $0.1 \mathrm{~s}$ ), substantially more pyknosed neurons were observed in CA1 and CA3 areas of the hippocampus and the neuronal count reduced significantly $(\mathrm{p}<0.05)$ compared to the control group (Table 1). At the higher dose of $1 / 5$ th $\mathrm{LD}_{50} \mathrm{CPF}$ with or without stress (CPF 0.2 and CPF $0.2 \mathrm{~s}$ ), pyknosis of pyramidal neurons as well as areas of vacuolation were observed in all three areas of hippocampus. The changes observed with swim stress (CPF $0.2 \mathrm{~s}$ ) were significant compared to the control but was not significant compared to CPF 0.2. Quantitative observations of the hippocampal pyramidal neurons showed that application of $1 / 10$ th $\mathrm{LD}_{50} \mathrm{CPF}$ for 1 week

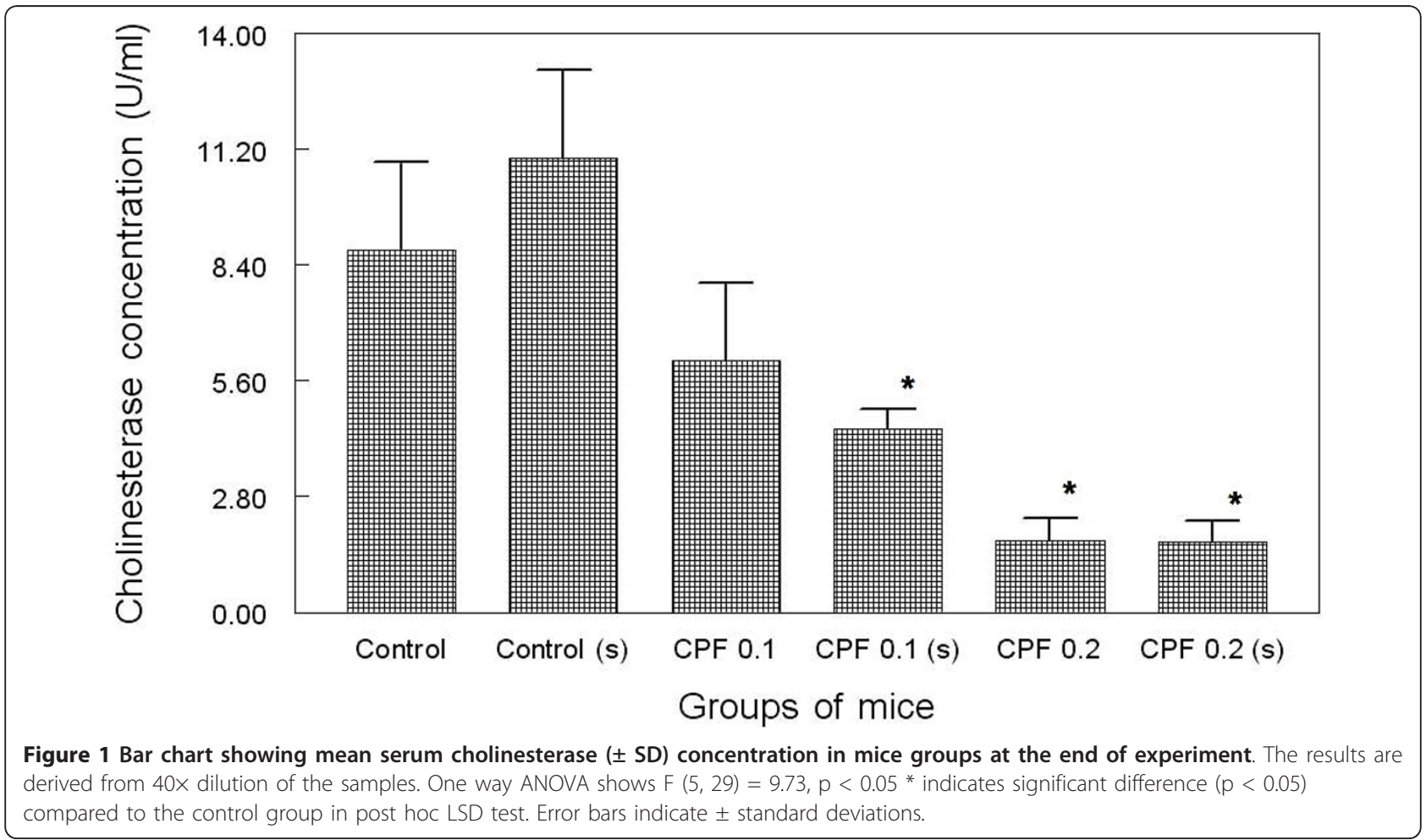




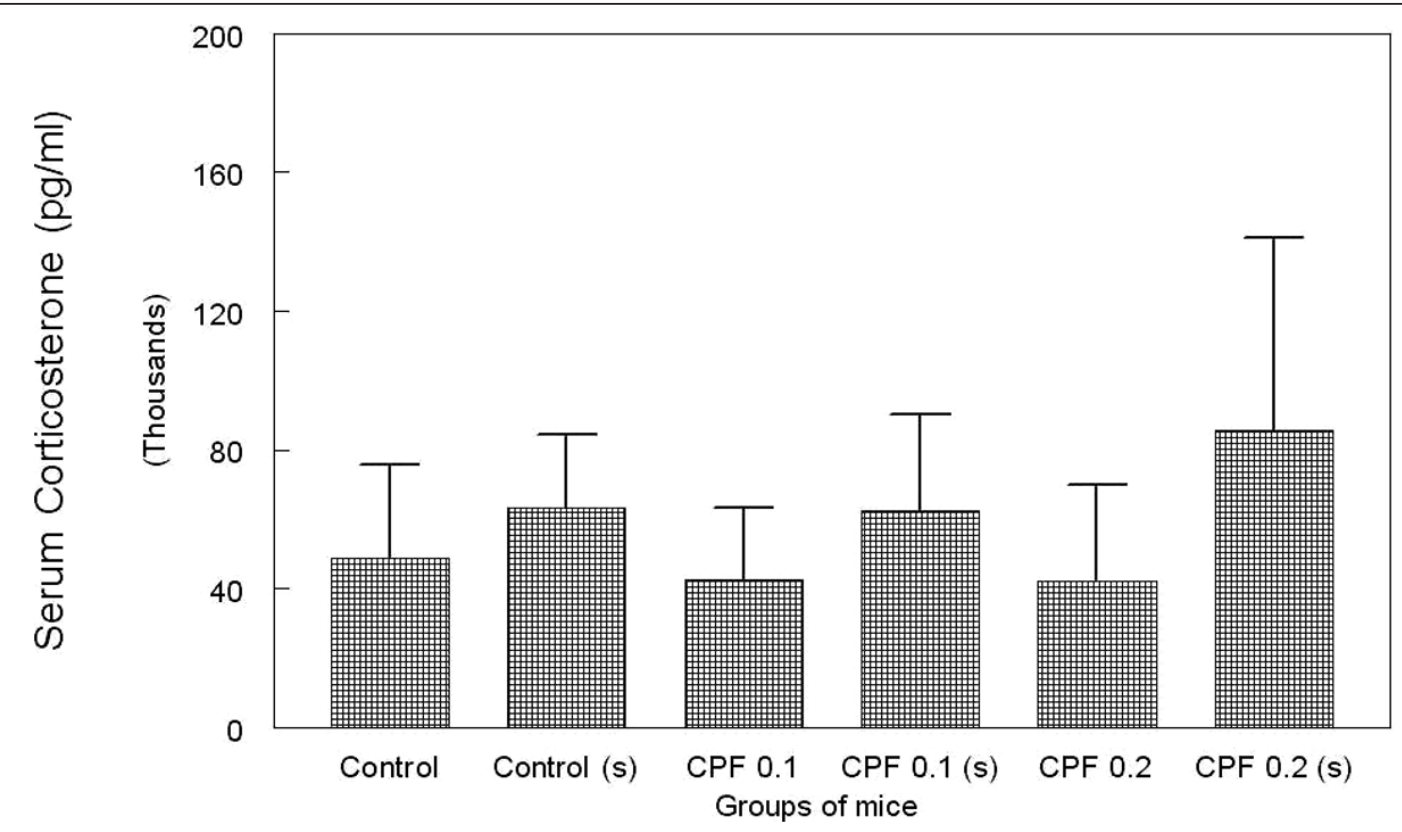

Figure 2 Bar chart showing mean serum corticosterone $( \pm S D)$ concentration in mice group at the end of experiment. The results are derived from $40 \times$ dilution of the samples. Error bars indicate \pm standard deviations.

(CPF 0.1) failed to significantly reduce neuronal density in the CA1 and CA2 areas of the hippocampus $(7.60 \%$ and $13.61 \%$ reduction respectively). In CPF $0.1 \mathrm{~s}$ group where swim stress was applied in conjunction with CPF, a significant reduction in neuronal density was now observed (15.11\% and $20.55 \%$ reduction respectively) compared to the control. However the reduction observed in neuronal count was not significantly different from CPF exposure alone (CPF 0.1).

\section{Changes observed in GFAP immunostaining}

Examination of the photomicrographs revealed that following one week of application, longer and more numerous astrocytic processes were observed in CPF 0.2 group compared to CPF 0.1 (Figure $3 \mathrm{C}$ and $3 \mathrm{~B}$ respectively) in stratum moleculare and stratum Oriens. Quantitative study showed that the astrocytic density was raised in all groups receiving CPF applications (Table 2). An increase of $37.21 \%$ in astrocytic density was observed in CPF 0.1 group (Figure $3 \mathrm{~B}$ ) compared to the control (Figure 3A), while a further increase was seen in CPF $0.2(41.08 \%)$ group (Figure $3 C$ ). When stress and CPF at doses of $1 / 10$ th dermal $\mathrm{LD}_{50}$ were applied concurrently (Figure 3B1), astrocytic density was not increased compared to $C P F$ at $1 / 10$ th dermal $\mathrm{LD}_{50}$ alone (Figure $3 \mathrm{~B}$ ). Increase in astrocytic density in CPF $0.2 \mathrm{~s}(47.40 \%)$ (Figure 3C) was greater compared to CPF 0.2 (41.08\%) (Figure 3C1). One way ANOVA followed by Post Hoc tests (Bonferroni) showed that groups CPF 0.1, CPF 0.1 $\mathrm{s}$, CPF 0.2 and CPF $0.2 \mathrm{~s}$ differed significantly from the control group $(\mathrm{p}<0.001)$ in the counts of astrocytic density in Stratum Moleculare-lacunosum of hippocampus but in Stratum Oriens, only CPF 0.1, CPF 0.2 and CPF $0.2 \mathrm{~s}$ differed significantly from the control group

Table 1 Table showing mean ( \pm SD) neuronal density in mice groups in different hippocampal areas at the end of the experiment

\begin{tabular}{cccc}
\hline Experimental Group & $\begin{array}{c}\text { Absolute neuronal density in CA1 } \\
\left(\text { per } \mathbf{~ m}^{2}\right)\end{array}$ & $\begin{array}{c}\text { Absolute neuronal density in CA2 } \\
\left(\text { per } \mathbf{~ m m}^{2}\right)\end{array}$ & $\begin{array}{c}\text { Absolute neuronal density in CA3 } \\
\left(\text { per } \mathbf{~ m m}^{2}\right)\end{array}$ \\
\hline Control & $881.8 \pm 134$ & $710.5 \pm 146$ & $640.7 \pm 75$ \\
Control(s) & $902.1 \pm 124$ & $662.9 \pm 156$ & $640.6 \pm 95$ \\
CPF 0.1 & $814.7 \pm 158$ & $613.8 \pm 125$ & $504.3^{*} \pm 116$ \\
CPF 0.1(s) & $748.5^{*} \pm 185$ & $564.5 \pm 100$ & $501^{*} \pm 119$ \\
CPF 0.2 & $768.7^{*} \pm 201$ & $578.7^{*} \pm 103$ & $483.3^{*} \pm 167$ \\
CPF 0.2(s) & $746.6^{*} \pm 163$ & $525.7^{*} \pm 96$ & $467.7^{*} \pm 119$ \\
\hline
\end{tabular}

Footnote:

* indicates significant difference $(p<0.05)$ compared to the control group in One Way ANOVA followed by Post Hoc Bonferroni test. 

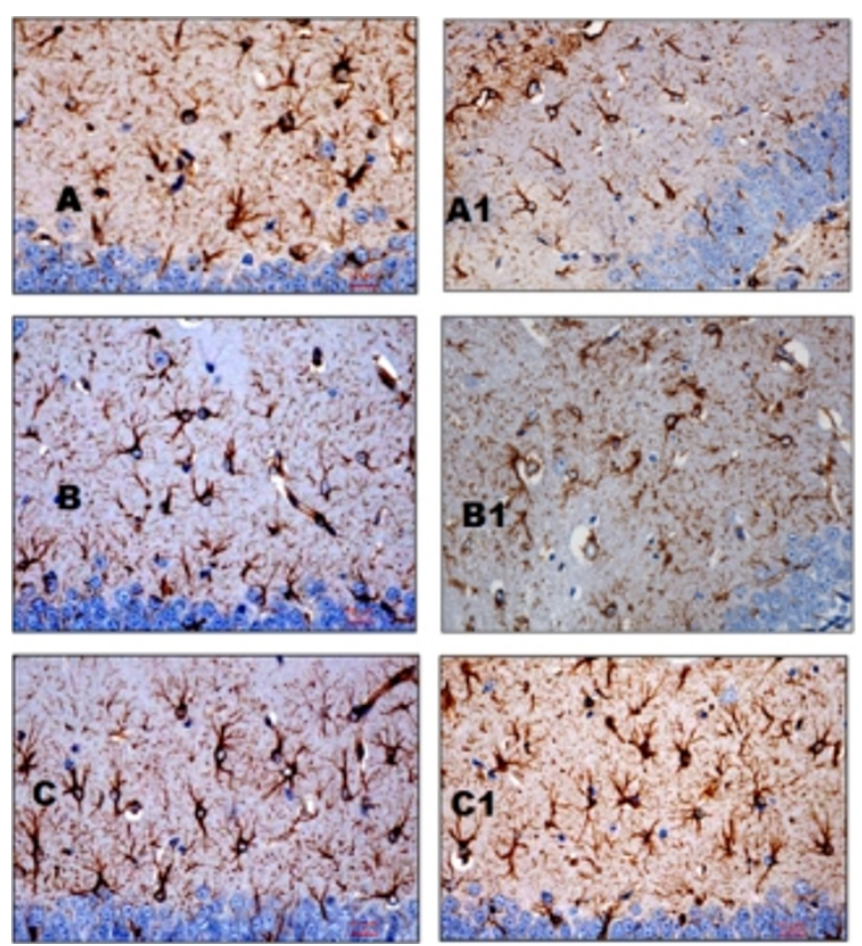

Figure 3 Photomicrograph showing the immunohistochemical staining of GFAP expression in stratum moleculare-lacunosum of the hippocampus in groups of mice at the end of experiment. Brown colour rounded cells with processes are the astrocytes. A-Control group; A1-Control (s) group; B-CPF0.1 group; B1-CPF 0.1 (s) group; C-CPF 0.2 group; C1-CPF 0.2 (s) group. (GFAP, 400x).

$(\mathrm{p}<0.05)$. In both the areas, no statistically significant increase in astrocytic density was found in CPF $0.1 \mathrm{~s}$ and CPF $0.2 \mathrm{~s}$ groups compared to CPF 0.1 and CPF 0.2 groups.

\section{Discussion}

Following 1 week of application of CPF, mean body weights of the mice receiving dermal applications of $\mathrm{CPF}$ were reduced compared to the control group. The weight loss observed in this study could be attributed to the effect of CPF causing cholinergic overstimulation, leading to increased gastric motility and a reduction in absorption [21]. Furthermore, cholinergic overstimulation of nicotinic receptors can cause increased muscular activity (fasciculation and tremors) and thus increases energy consumption. Daily applications of CPF for seven days at the lower dose $\left(1 / 10\right.$ th dermal $\left.L_{50}\right)$ could reduce plasma cholinesterase activity compared to control group (without stress, 30.5\% reduction and with stress, $49.8 \%$ reduction) but the reduction in CPF only group was not statistically significant. The reduction in stressed group was statistically significant compared to the control. Similar to the findings in this study, a previous study found that subsequent to daily low dose $\left(12 \% \mathrm{LD}_{50}\right)$ injection of the OP soman to mice for three days, plasma cholinesterase activities were inhibited by $32 \%$ [22]. In a separate study, 14 days after dermal applications of OP diisopropylfluorophosphate (DFP) to

Table 2 Table showing the mean $( \pm$ SD) astrocytic density in stratum moleculare-lacunosum and stratum oriens of hippocampus in mice groups at the end of experiment

\begin{tabular}{lll}
\hline Groups & Stratum Moleculare-lacunosum $\left(\right.$ per $\left.\mathbf{~ m m}^{2}\right)$ & Stratum Oriens $\left(\mathbf{p e r} \mathbf{~ m m}^{2}\right)$ \\
\hline Control & $256.9 \pm 53$ & $125 \pm 54$ \\
Control (s) & $284.3 \pm 67$ & $125 \pm 54$ \\
CPF 0.1 & $352.6 \pm 99^{*}$ & $193.3 \pm 62^{*}$ \\
CPF $0.1(\mathbf{s})$ & $343.9 \pm 85^{*}$ & $164.7 \pm 64$ \\
CPF 0.2 & $362.5 \pm 96^{*}$ & $202.8 \pm 91^{*}$ \\
CPF $0.2(\mathbf{s})$ & $378.7 \pm 83^{*}$ & $241.2 \pm 64^{*}$ \\
\hline
\end{tabular}

Footnote:

* indicates significant difference $(p<0.001)$ compared to the control in One Way ANOVA followed Post Hoc Bonferroni test. 
monkeys at low doses of $0.01 \mathrm{mg} / \mathrm{kg} \mathrm{BW}$, cholinesterase activity was reduced by $76 \%$ [23]. A single dermal application of CPF in humans for four hours absorbed CPF very little $(4.3 \%)$, and CPF was not completely eliminated from the body even after 120 hours, suggesting accumulation of CPF in the body [24]. The CPF applied in this study was dissolved in the xylene, which is an organic solvent. As organic solvents dissolve fat, xylene can be easily absorbed by the layer of fat in the skin.

Compared to the previous study by this author [8], where application of swim stress and CPF $\left(1 / 5^{\text {th }} \mathrm{LD}_{50}\right)$ for 21 days facilitated the reduction in serum cholinesterase by $19.7 \%$ (compared to only application of CPF), this study showed that application of stress for lower duration (7 days) with lower dose of CPF (1/10th $\left.\mathrm{LD}_{50}\right)$ can bring down the serum cholinesterase levels by similar level (19.3\%). The shorter duration of stress might not have potentiated the neurotoxic effects of CPF enough in all the mice. Hence the changes observed with stress remained statistically insignificant compared to the CPF only groups but became significant compared to the control.

Qualitative observations of the hippocampal neurons in this study showed that following seven days of low dose CPF application (1/10th dermal $\left.\mathrm{LD}_{50}\right)$, no apparent damage to the neurons was visible. However at the higher dose $\left(1 / 5\right.$ th dermal $\left.L D_{50}\right)$, seven days of application resulted in visible damage in the form of pyknosis. Dendritic morphology was assessed in the prefrontal cortex, CA1 area of the hippocampus and the nucleus accumbens following repeated (14 days) low dose intraperitoneal application of OP malathion $(40 \mathrm{mg} / \mathrm{kg} \mathrm{BW})$ in mice. Dendritic length in the hippocampus and prefrontal cortex, and density of dendritic spines in all the three areas assessed were reduced [25]. As part of the trisynaptic circuit, afferent inputs to the hippocampus are first sent to the dentate gyrus, which then projects to the CA3 area. The CA3 neurons then send projections to CA1. Dendrites of CA1 neurons project to the subiculum and then back to the entorhinal cortex. CA3 being an early structure in this circuit, it is the first part of the hippocampus to be affected by cholinergic overactivity. This could explain the neuronal reduction observed only in CA3 after application of low dose CPF (1/5th dermal $\mathrm{LD}_{50}$ ) for seven days. Agricultural workers chronically exposed to low-levels of CPF and other pesticides were found performing poorly on neurobehavioral tests [4]. Following occupational exposure to CPF, functional deficits in cognitive tests of abstraction, concentration and memory have also been reported [26,27]. These functional deficits can be extrapolated to be caused by prolonged exposure to low dose CPF.

Quantitative examination of the hippocampal neurons showed that consequent application of stress and CPF (1/10th and $1 / 5$ th dermal $\left.\mathrm{LD}_{50}\right)$, even for seven days, showed marked reduction in neuronal density in all areas of the hippocampus. Neuronal density in the CA3 area of the hippocampus was also shown to be significantly reduced in rats after prolonged pain stress in the form of 13 min electric shocks for 15 days [28]. It has been proposed that alterations in the cholinergic neurotransmitter systems due to stress are the initial events contributing to CNS impairment and that exacerbation of injury could occur with the concurrent exposure of stress and cholinesterase inhibitors [29]. Previous study by the authors showed that toxicity on hippocampal neurons following three-weeks-long applications of CPF at high doses $(1 / 2$ dermal $\mathrm{LD}_{50}$ ) could be exacerbated by exposure to swim stress [8]. It was reported that compared to just CPF application $\left(1 / 2\right.$ dermal $\left.\mathrm{LD}_{50}\right)$, CPF with stress increased the reduction in neuronal density by $30 \%, 12 \%$ and $26.7 \%$ in the CA1, CA2 and CA3 areas of the hippocampus respectively. This study showed that the application of $1 / 10$ th dermal $\mathrm{LD}_{50}$ CPF with stress for 7 days only showed many pyknosed neurons surrounded by vacuolation of neuropil in the CA1and CA3 sub-fields of the hippocampus and the neuronal count was significantly reduced $(\mathrm{p}<0.05)$ compared to the control. These changes were less apparent after application of CPF $\left(1 / 10\right.$ th dermal $\left.\mathrm{LD}_{50}\right)$ only. The current study has shown that stress with dermal application of CPF can cause hippocampal damage only after seven days of application at a much lower dose $\left(1 / 10\right.$ dermal $\left.L_{50}\right)$. Stress has been demonstrated to increase permeability of the BBB to foreign chemicals [10]. Thus the increased permeability could have caused the increased toxicity of CPF on the hippocampal neurons observed in this study.

Following one week of CPF application at both doses $\left(1 / 10\right.$ th and $1 / 5$ th dermal $\left.\mathrm{LD}_{50}\right)$, GFAP expression as measured by astrocytic density was significantly increased compared to the control group. GFAP expression has been found to be increased following toxic insult to the CNS in many studies. A single subcutaneous injection $\left(50 \mu \mathrm{g} / \mathrm{kg}\right.$ bw, $\left.1 / 2 \mathrm{LD}_{50}\right)$ of the cholinesterase inhibitor Sarin was found to significantly increase GFAP levels in the cerebral cortex by $269 \%$ after one hour, and to $318 \%$ after two [30]. Extended studies in rats on the effects of gestational exposure to cholinotoxicants nicotine and $\mathrm{CPF}$, alone and in combination, showed increased GFAP expression in offspring in the CA1 sub-field of the hippocampus, and white matter and granular cell layer of the cerebellum $[17,18]$. In the present study, GFAP expression was increased in the groups receiving combined treatments of stress and CPF 0.2 dosage as compared to those just receiving CPF 0.2 dosage, but the increase was not significant. The application of swim stress with CPF 0.1 dosage did not increase the GFAP expression compared to that in CPF 0.1 dosage only. The findings 
suggest that toxicity resulting from stress leads to increase in GFAP expression in response to greater injury to the hippocampus with higher sub-toxic dose of CPF. Qualitative examination showed that following seven days of CPF application, GFAP expression in the astrocytes was more prominent compared to the control groups. The astrocytic processes of the groups receiving $\mathrm{CPF}$ were longer, and greater in number. This may be attributed to the neuroprotective effect of astrocytes limiting neuronal damage. It has been suggested that the metabolites of CPF, trichloropyridinol (TCP), exert strong toxic effects on astrocytes, compromising their neuroprotective effects and thus increasing the neurotoxicity of CPF [31]. The neuroprotective effects of astrocytes have been suggested in many studies. To assess the influence of glial cells on the neurotoxicity of OPs, aggregate brain cell cultures of foetal rat telencephalon were treated with CPF and parathion for 10 days. This in vitro study found that the neurotoxicity of CPF and parathion was increased in aggregate cultures deficient in glial cells [31]. When an acute dose of the OP diisopropylfluorophosphate (DFP) was injected subcutaneously into hens, the authors discovered that GFAP expression studied in total RNAs extracted from non-susceptible parts of cerebrum was upregulated from first 2 days, indicating a neuroprotective effect from anticipated imminent neurotoxicity [32].

\section{Conclusions}

In conclusion, dermal application of low dose of CPF $\left(1 / 10\right.$ th dermal $\left.\mathrm{LD}_{50}\right)$ for seven days, was not capable of producing neurotoxicity in all areas of the hippocampus in the parameters of cholinesterase inhibition and neuronal density reduction. The addition of swim stress with CPF exposure caused reduction in serum cholinesterase and neuronal density of the hippocampus which was significant compared to control but not significantly different from $\mathrm{CPF}$ exposure alone. An interesting finding of the study was that dermal application of low dose of CPF for 7 days significantly increased GFAP expression, indicating that it can be used as a marker for CPF toxicity at the early stages. It is suggested that astrocytes may provide neuroprotective effects against CPF toxicity. Therefore, it is important that pesticide applicators should not be exposed dermally to pesticides continuously for extended periods to avoid damage to the CNS. It is also imperative that such individuals should not work under stressful conditions, as these conditions can produce neurotoxic effects.

\section{Acknowledgements}

The research is supported by the grant from the research and ethics committee of International Medical University

\section{Author details}

'Postgraduate \& Research Department, International Medical University, No.126, Jalan 19/155B, Bukit Jalil, 57000, Kuala Lumpur, Malaysia. ${ }^{2}$ Pathology Department, International Medical University, No.126, Jalan 19/155B, Bukit Jalil, 57000, Kuala Lumpur, Malaysia. ${ }^{3}$ Human Biology Department, International Medical University, No.126, Jalan 19/155B, Bukit Jalil, 57000, Kuala Lumpur, Malaysia.

\section{Authors' contributions}

NKM and VDN designed the study. KL and AT conducted the study. NKM conducted statistical analysis of the collected data. All authors have contributed, read and approved the final manuscript.

\section{Competing interests}

The authors declare that they have no competing interests.

Received: 15 September 2010 Accepted: 8 March 2011

Published: 8 March 2011

\section{References}

1. Rathinam X, Kota $R$, Thiyagar N: Farmers and formulations-rural health perspective. Med J Malaysia 2005, 60(1):118-123.

2. Sullivan JB Jr, Blose J: Organophosphate and carbamate insecticides. In Hazardous materials toxicology: Clinical principles of environmental health. Edited by: Sullivan JB, Krieger GR. Williams and Wilkins, Philadelphia; 1992:1015-1026.

3. Kiely T, Donaldson D, Grube A: 2000 and 2001 Usage. Pesticides Industry Sales and Usage, 2000 and 2001 Market Estimates. Unites States Environmental Protection Agency [http://www.epa.gov/pesticides/pestsales/ 01 pestsales/market_estimates2001.pdf], Last accessed on 21 Feb 2011.

4. Rothlein J, Rohlman D, Lasarev M, Phillips J, Muniz J, McCauley L: Organophosphate pesticide exposure and neurobehavioral performance in agricultural and non-agricultural Hispanic workers. Environ Health Perspect 2006, 114(5):691-696.

5. Kaplan JG, Kessler J, Rosenberg N, Pack D, Schaumburg HH: Sensory neuropathy associated with Dursban (chlorpyrifos) exposure. Neurology 1993, 43:2193-2196.

6. Abu Qare AW, Abdel Rahman A, Brownie C, Kishk AM, Abou Donia MB: Inhibition of cholinesterase enzymes following a single dermal dose of chlorpyrifos and methyl parathion, alone and in combination, in pregnant rats. J Toxicol Environ Health A 2001, 63(3):173-189.

7. Qiao D, Seidler FJ, Abreu Villaca Y, Tate CA, Cousins MM, Slotkin TA: Chlorpyrifos exposure during neurulation: cholinergic synaptic dysfunction and cellular alterations in brain regions at adolescence and adulthood. Brain Res Dev Brain Res 2004, 148(1):43-52.

8. Mitra NK, Nadarajah VD, Siong HH: Effect of concurrent application of heat, swim stress and repeated dermal application of chlorpyrifos on the hippocampal neurons in mice. Folia Neuropathol 2009, 47(1):60-68.

9. Gordon CJ, Leon LR: Thermal stress and the physiological response to environmental toxicants. Rev Environ Health 2005, 20(4):235-263.

10. Friedman A, Kaufer D, Shemer J, Hendler I, Soreq H, Tur-Kaspa I: Pyridostigmine brain penetration under stress enhances neuronal excitability and induces early immediate transcriptional response. Nature Med 1996, 2:1382-1385.

11. Norenberg M: Astrocyte responses to CNS injury. I Neuropathol Exp Neurol 1994, 53:213-220.

12. Abou-Donia MB, Khan WA, Suliman HB, Abdel-Rahman AA, Jensen KF: Stress and combined exposure to low doses of pyridostigmine bromide, DEET, and permethrin produce neurochemical and neuropathological alterations in cerebral cortex, hippocampus, and cerebellum. J Toxicol Environ Health 2004, 67(2):163-192.

13. Eng LF, Ghirnikarz RS: GFAP and Astrogliosis. Brain Pathol 1994, 4:229-237.

14. Ho G, Zhang C, Zhuo L: Non-invasive fluorescent imaging of gliosis in transgenic mice for profiling developmental neurotoxicity. Toxicol Appl Pharmacol 2007, 221(1):76-85.

15. O'Callaghan JP: Assessment of neurotoxicity: use of glial fibrillary acidic protein as a biomarker. Biomed Environment Sci 1991, 4:197-206.

16. O'Callaghan JP, Jensen KF: Enhanced expression of glial fibrillary acidic protein and the cupric silver degeneration reaction can be used as sensitive and early indicators of neurotoxicity. Neurotoxicol 1992, 13:113-122. 
17. Abdel-Rahman A, Dechkovskaia A, Mehta-Simmons H, Guan X, Khan W, Abou-Donia M: Increased expression of glial fibrillary acidic protein in cerebellum and hippocampus: differential effects on neonatal brain regional acetylcholinesterase following maternal exposure to combined chlorpyrifos and nicotine. J Toxicol Environ Health A 2003, 66(21):2047-2066.

18. Abdel-Rahman A, Dechkovskaia AM, Mehta-Simmons H, Sutton JM, Guan X, Khan WA, Abou-Donia MB: Maternal exposure to nicotine and chlorpyrifos, alone and in combination, leads to persistently elevated expression of glial fibrillary acidic protein in the cerebellum of the offspring in late puberty. Arch Toxicol 2004, 78(8):467-476.

19. Singh A, Naidu PS, Gupta S, Kulkarni SK: Effect of Natural and Synthetic Antioxidants in a Mouse Model of Chronic Fatigue Syndrome. J Med Food 2002, 5(4):211-220.

20. Abercrombie M, Johnson ML: Quantitative histology of Wallerian degeneration: I. Nuclear population in rabbit sciatic nerve. J Anat 1946, 80:37-50.

21. Jones AL, Karalliedde L: Poisoning. In Davidson's Principles and Practice of Medicine. 20 edition. Edited by: Boon NA, Colledge NR, Davidson SS, Walker BR. Edinburgh: Churchill Livingstone; 2006:203-226.

22. Christin D, Dalon S, Delamanche S, Perrier P, Breton P, Taysse L: Effects of repeated low-dose soman exposure on monoamine levels in different brain structures in mice. Neurochem Res 2008, 33:919-926.

23. Prendergast MA, Terry AV Jr, Buccafuscoa JJ: Effects of chronic, low-level organophosphate exposure on delayed recall, discrimination, and spatial learning in monkeys and rats. Neurotoxicol Teratol 1998, 20(2):115-122.

24. Meuling WJ, Ravensberg LC, Roza L, van Hemmen JJ: Dermal absorption of chlorpyrifos in human volunteers. Int Arch Occup Environ Health 2005, 78(1):44-50.

25. Campaña AD, Sanchez F, Gamboa C, Gómez-Villalobos Mde J, De La Cruz F, Zamudio S, Flores G: Dendritic morphology on neurons from prefrontal cortex, hippocampus, and nucleus accumbens is altered in adult male mice exposed to repeated low dose of malathion. Synapse 2008, 62(4):283-290.

26. Savage E, Keefe T, Mounce L, Heaton R, Lewis J, Burcar P: Chronic neurological sequelae of acute organophosphate pesticide poisoning. Arch Environ Health 1990, 43:38-45.

27. Steenland K, Jenkins B, Ames R, O'Malley M, Chrislop D, Russo J: Chronic neurological sequelae to organophosphate pesticide poisoning. Am $J$ Pub Health 1995, 84:731-736.

28. Shiryaeva NV, Vshivtseva W, Mal'tsev NA, Sukhorukov VN, Vaido Al: Neuron density in the hippocampus in rat strains with contrasting nervous system excitability after prolonged emotional-pain stress. Neurosci Behav Physiol 2008, 38(4):355-357.

29. Pung T, Klein B, Blodgett D, Jortner B, Ehrich M: Examination of concurrent exposure to repeated stress and chlorpyrifos on cholinergic, glutaminergic and monoamine neurotransmitter systems in rat forebrain region. Int J Toxicol 2006, 25(1):65.

30. Damodaran TV, Bilska MA, Rahman AA, Abou-Doni MB: Sarin causes early differential alteration and persistent overexpression in mRNAs coding for glial fibrillary acidic protein (GFAP) and vimentin genes in the central nervous system of rats. Neurochem Res 2002, 27(5):407-415.

31. Zurich MG, Honegger P, Schilter B, Costa LG, Monnet-Tschudi F: Involvement of glial cells in the neurotoxicity of parathion and chlorpyrifos. Toxicol Appl Pharmacol 2004, 201 (2):97-104.

32. Damodaran TV, Abou-Donia MB: Alterations in levels of mRNAs coding for glial fibrillary acidic protein (GFAP) and vimentin genes in the central nervous system of hens treated with diisopropyl phosphorofluoridate (DFP). Neurochem Res 2000, 25(6):809-816.

doi:10.1186/1745-6673-6-4

Cite this article as: Lim et al:: The effect of consequent exposure of stress and dermal application of low doses of chlorpyrifos on the expression of glial fibrillary acidic protein in the hippocampus of adult mice. Journal of Occupational Medicine and Toxicology 2011 6:4.

\section{Submit your next manuscript to BioMed Central and take full advantage of:}

- Convenient online submission

- Thorough peer review

- No space constraints or color figure charges

- Immediate publication on acceptance

- Inclusion in PubMed, CAS, Scopus and Google Scholar

- Research which is freely available for redistribution 